\title{
RESPUESTA A M. ATIENZA
}

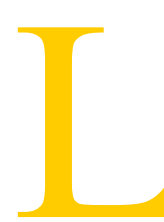

os primeros sentimientos que tuve al leer el artículo de Manuel Atienza, Discutamos sobre paternalismo, fueron de preocupación y agradecimiento. La preocupación se debió a la dificultad de contestar su réplica. El agradecimiento porque una réplica como la que él hizo a nuestros trabajos es una guía inmejorable para aclarar algunos puntos, para explicar otros y sobre todo para seguir pensando en el tema.

Trataré, brevemente, de aclarar algunas cuestiones. Atienza ve en mi trabajo una cierta ambigüedad entre el sentido peyorativo que le doy al término «paternalismo» y mi idea de que éste se puede justificar. Lo que yo creo es que de hecho el término «paternalismo» es peyorativo en el mismo sentido en que «guerra» y «castigo» lo son. Esto significa que preferiríamos encontrarnos en situaciones en las que no hubiera acciones paternalistas, guerras o castigos. Ahora bien, esto no significa que no se pueda o se deban justificar cuando las situaciones así lo exigen.

En una parte de su trabajo Atienza afirma que Victoria Camps y yo añadimos una tercera condición a la definición de paternalismo, a saber, que se trata de conductas y normas injustificadas éticamente. Mi defensa es parcial, pues por una parte creo que la aceptación de la definición de paternalismo de Van de Veer me exime de ese cargo, pero por otra reconozco que la distinción entre los casos en los que se requiere una justificación ética y los casos en que recurrimos a otro tipo de justificación necesitaría más precisión.

Un punto que merece aclaración es el relacionado con el problema de las preferencias. Atienza se refiere a ello cuando afirma que no es necesario el cambio de preferencias para caracterizar una interferencia paternalista. Esto se debe a que, según él, hay casos en los que sencillamente no se consideran las preferencias de una persona. Confieso que no me queda claro a que se refiere Atienza cuando habla de «no considerar las preferencias de una persona». Si aceptamos la definición de una acción 
paternalista como una interferencia, tenemos que hablar de una acción contraria a las preferencias. El término «preferencia» es usado en un sentido amplio como la externalización de una decisión y no necesariamente como el resultado de una deliberación. Podemos decir que un niño prefiere quedarse en su casa jugando que ir a la escuela y por ello es necesaria la interferencia paternalista. Por esta razón no creo que podamos hablar de paternalismo en el caso de las generaciones futuras.

Ahora bien, me parece que en todo caso la discusión tendría que centrarse en torno a la noción de interferencia y no tanto en torno a la preferencia.

Este punto me remite a la cuestión de la persuasión. Estoy de acuerdo con Atienza que es necesario distinguir los dos supuestos que él menciona, sobre todo para diferenciar las acciones paternalistas de aquellas que no lo son.

El último punto que trataré es el que se refiere a la pluralidad de criterios para justificar una acción paternalista. No intento hacer una justificación ética oportunista. Quizá lo que propondría es una justificación pragmática. Creo, por ejemplo, que si alguien deposita una cantidad de dinero en el banco a plazo fijo y posteriormente desea gastar el dinero antes de que venza dicho plazo, la acción del banco al impedir cobrar el dinero es una acción que se justifica con el argumento del consentimiento pasado. En el caso de una persona que desea cruzar un río sin saber que el puente está roto la interferencia puede justificarse recurriendo al argumento de los riesgos. En el caso de los menores de edad o de las personas con lesiones cerebrales, se puede aplicar el criterio de los incapacitados básicos. Pero repito, esta cuestión más que de oportunismo me parece de pragmática.

Comparto la idea de Thomas Nagel en su artículo «La Fragmentación de los valores» (en La muerte en cuestión, Fondo de Cultura Económica, México, 1984), de que la justificación de nuestras acciones morales puede tener un origen distinto. A veces justificamos una acción en términos de un cálculo utilitario, otras en términos de los derechos humanos, otras en términos de ciertas necesidades. Me parece que esta posición es más realista que la postura ideal de lograr un criterio único de justificación.

\section{DOXA 5 (1988)}

